\title{
Internationalisation and the Future of the School of Government
}

\author{
Gary Hawke
}

The School of Government has achieved a good deal in its first five years. This includes developing a strategic studies programme to go beside those in public management and public policy, and ensuring that students can move among these programmes. There is still work to be done to get the most out of our suite of programmes, and one of the chief tasks of the next five years is to enhance the international element in our teaching and research.

\section{Origins}

Success has many patrons, while failure is an orphan. I am therefore glad that there are numerous versions of the origins of the School of Government.

The path that was obvious to me included a report which Simon Murdoch wrote when he was a visiting fellow at the university, and a working party in which I participated which was chaired by Matthew Palmer, the pro-vice-chancellor and dean of law. There were intervening steps, but while they kept alive the idea of a school of government they did not have a direct influence on the crucial decisions. Matthew Palmer, reporting to the then vice-chancellor, Stuart McCutcheon, managed the creation of the School of Government.

On several occasions I have heard state services commissioner Mark Prebble remark that senior public servants were impressed that after they had commented on how difficult it was to relate to the university, Victoria reorganised itself and provided an appropriate mechanism.

Mathew's report established a mission and vision for the school. I have usually simplified it to something like 'bringing academic expertise and knowledge to bear on the problems of the public sector as perceived by the public sector' - I always had it in mind that we might assist the public sector to share our view of what is important, but we would rely on persuasion, not on any authority of our own.

We developed the even simpler slogan, 'building capability in the public sector', which is not a matter of deep learning or precision but which captures the core of what we are about. It is because I expect international considerations to be more important to the capabilities of the future public sector that I expect it to require more from the School of Government.

\section{Objectives}

When I accepted the position of head of school, I spelt out in a letter to Matthew of 2 December 2002 how we should understand the mission of the school. It included some very important points (which were eventually achieved):

i There will be a dedicated carpark for the head of the School of Government at Rutherford House or Old Government Buildings at a cost to me no more than the minimum charged elsewhere for reserved outdoor carparks on the Kelburn or OGB campuses.

ii The university will maintain Macintosh computing facilities for the HoS while I occupy the position.

It also spelt out some key components of what the school could be expected to achieve, including:

a The overall objective of the appointment is to develop a thriving School of Government which attracts a field of appointable candidates to be the second $\mathrm{HoS}$ in five years' time.

b In elucidating the term, 'thriving' in para a above, attention will be focused not only on the ambitions of VUW as the university in the capital city, but also on the very real constraints on the investment which the University is able to make in the School 
of Government. ... university decisions which affect the income of the School of Government from EFTS will affect equally what is expected from the School.

c The vice-chancellor is committed to facilitating the development of the School of Government as a key element in the university's strategic vision and accepts that this requires personal support in developing and maintaining relationships with the public sector and in assisting the School to be an effective gateway for the public sector to all the resources of the university. (I accept that we do not want a cumbersome set of institutions which require the vice-chancellor's time and will look for appropriate streamlining.)

We achieved the overall objective of what is clause $\mathrm{a}$ above. Clauses $\mathrm{b}$ and $\mathrm{c}$ established the important external objective of the school: using available resources to make the public sector value university knowledge and expertise. Matthew and I were content to leave implicit that this was to be achieved through teaching and research. The university has a clear statutory objective, 'the advancement of knowledge, and the dissemination and maintenance thereof, by teaching and research', and we were part of the university. Furthermore, it was the credibility of independent analysis that made the public sector want ready access to the university through a school of government.

\section{External focus}

The School of Government was intended to have an external focus. We can claim considerable success in achieving it. I have written elsewhere on our successes and challenges in our teaching and learning programmes (Hawke, forthcoming), and here I want to concentrate on our research-related activities. These mostly relate to the 'advancement of knowledge', but the drafters of the university objective were clearly aware that both teaching and research could contribute to all of the aims of advancement, maintenance and dissemination, and that is certainly how I envisaged the activities of the School of Government.

The school generates a range of research. It was formed by bringing together an existing teaching activity with the Institute of Policy Studies and its satellite research centres. In five years we have made progress towards aligning the incentives and interests of the component parts, more slowly than some of our public sector stakeholders thought appropriate and more rapidly than some of my colleagues wished. The range will always include individual scholars pursuing their own interests and generating standard scholarly publications, whether or not through joint publications with other scholars who have similar interests. It will extend to consultancy on contemporary issues of management and policy development. The standard classifications of the Frasciati manual of basic, strategic and operational research are all appropriate for the School of Government. However, the school should have a particular interest in shaping knowledge about emerging issues that will require new capabilities in the public sector.

I think we were right to preserve the brand of 'IPS', but increasingly we have presented ourselves as SoG. In my view, we should work towards IPS being the arm of the school that does research of a 'public good' character - activities, including publication, which are aimed at public knowledge required for collective responses to policy questions - while the school also engages in consultancy, practice-based teaching which includes the creation and dissemination of new knowledge, and conventional academic research and publication.

Our major achievements include the Emerging Issues Programme and the VUWSoG Trust. The former is a research programme aimed at enhancing the capabilities of the school to achieve its mission, funded by contributions from all public sector departments and governed by a steering committee of departmental chief executives who can report to the Chief Executives Forum. It has generated research on the relationship between public servants and Parliament, on the Pacific, on ageing and on climate change, and more new knowledge on emerging issues important to the public sector is currently under way.

The government noticed our success in both teaching and research, and established a trust fund of $\$ 4$ million to finance those aspects of the School of Government that are not readily provided for through conventional funding of university teaching and research. It gives a source of finance for research which does not lend itself to publication in academic journals, and to practicebased teaching and learning which goes beyond what is funded through Vote: Education. At the same time, the government provided a capital endowment to ANZSOG, the Australia and New Zealand School of 
Government, and trans-Tasman issues will be prominent in the activities funded by the VUWSoG Trust.

\section{Internationalisation}

Focusing on public sector problems as seen by the public sector does not imply passive, tame academics working to somebody else's direction. It means accepting the responsibility to persuade public servants to share our view of the importance of some issues, and if we cannot succeed in such persuasion then turning our attention elsewhere. Within this, I think a particular role is persuading public servants to pay attention to connections that might otherwise be overlooked. I want to illustrate this from three examples where I have been working personally; other members of the School of Government could add many more.

Because of my role over many years in the Pacific Economic Co-operation Council, and through my participation in the Council for Security Co-operation in Asia Pacific, which I inherited with the School of Government, I have had a personal interest in Asia literacy and relations with Asia. When the New Zealand Asia Foundation was created in the early 1990s (initially as the Asia 2000 Foundation) the Institute of Policy Studies co-operated with it in several initiatives, and we have not moved forward as much as I would wish. I do not think we have built enough understanding of Asia into our thinking about policy developments and I expect this to loom large in the future work of the School of Government. Our teaching programmes must eventually be affected, but first there is research to be done, not so much research about Asia, but understanding of Asia built into research about policy and management.

The recent white paper on relations with Asia (MFAT, 2007) includes lots of sensible material, but much of it could have been written in the early 1990s. We can certainly still wish for a more learned media, but in fact the internet makes Asian news available to those who want it and New Zealand commentary on Asian affairs will follow when New Zealanders see its importance. We achieve more by creating commentary about Asia from a New Zealand perspective than by lamenting its absence. We can regret absence of Asian material from teaching programmes, but what are we doing to show that Asia is relevant to the learning in which people are interested? Much of the discussion is about Asian content in courses, but what is more important is exploration of how abstract learning facilitates learning about Asia, and how Asian thinking relates to the abstract learning which we value.

What most disappoints me is how little recognition of Asia has penetrated into additional areas of policy. An obvious current example is climate change, where the work of my colleagues under the leadership of Jonathan Boston has had a significant impact in policy circles. Even that work, however, has been Eurocentric. It assumes that international agreement and the Kyoto Protocol are synonymous. Climate change figured strongly on the APEC agenda in 2007, and media reporting was almost entirely in terms of points-scoring about John Howard and George Bush, including how they still had not signed up to the Kyoto commitments of developed economies. The media reflected discussion in policy circles; commentary missed the most significant news, which was not the humorous points-scoring from $\mathrm{Hu}$ Jin Tao about countries failing to meet commitments, but the clear assertion by Asian economies that while Europeans and Anglo-Saxons might like the notion of defined commitments and monitoring processes, Asian preferences are different.

The balance between binding and voluntary commitments has been much discussed and experienced within APEC. New Zealand policy thinking should learn from that. All nations are selective in what they attach importance to. The Nuclear Non-proliferation Treaty had three components: no additions to the existing nuclear-weapon states; disarmament by the nuclear-weapon states; and facilitation of access to nuclear technology for peaceful purposes. There is no sign that the nuclear-weapon states, including the UK, US and France, will pay attention to their commitment to reduce nuclear stockpiles and facilitate dissemination of nuclear technologies, no matter how much they argue for effective monitoring of non-proliferation. European Union countries rapidly found reasons not to enforce the sanctions of the Maastricht treaty when its provisions proved inconvenient. Members of the US Congress find nothing incongruous in proposing legislation to discriminate against China, in clear contravention of US commitments under international trade law, while proclaiming the sanctity of the 'rule of law' and the impossibility of changing US domestic law which requires trade agreements to be reciprocal. The notion 
that Kyoto commitments will be treated as sacrosanct by EU members is implausible.

Nothing in these observations justifies a cavalier attitude towards international commitments. They point towards the inadequacy of simplistic argument that takes a selective approach to international agreements. The content of international agreements is frequently complex and overlapping. Isolating particular provisions which are useful for foreclosing domestic debate about how international commitments should be built into policy design and implementation is not a desirable way to develop policy positions.

As Barry Desker has argued (Desker, 2007a), Asia will act on climate change but will not accept Kyototype commitments: 'An approach which emphasises changing the norms, exerting influence on major carbon emitters and obtaining consensual agreements is much more likely to succeed. ${ }^{\prime}$ Anybody who has looked at the history of early voluntary sector liberalisation and accelerated tariff liberalisation in APEC in the mid1990s will recognise the sense of that. It may take a while to develop understanding in the EU and among activists. But if we had made the progress in Asia literacy we anticipated in 1993, it would now be part of our policy discussion. We would not be talking about 'binding verifiable commitments' versus consensual development of goals, but working directly on how we manage various kinds of agreements. ${ }^{2}$

Some old-fashioned policy analysis would help anyway. The design of Kyoto is very much in the interests of Europe, and the standard division between developed and developing countries is misleading. A World Bank study (Buys et al., 2007) defines 'two dimensions' of vulnerability to climate change: 'impact vulnerability' - weather events and sea level rises; and 'source

See also RSIS Commentary 95/2007 (7 September 2007) were he adds: 'However, the Kyoto approach of prescriptive, legally binding obligations will be resisted in East Asia. ... This is where an APEC initiative could be effective as it would mark a move away from the Kyoto model and bring on board China, Indonesia as well as the United States.' Barry Desker is a former Singaporean ambassador to Indonesia who heads the Rajaratnam School of International Studies at Nanyang Technical University. He should be better known than he is to a wide range of policy analysts in Wellington.

2 Thomas Fuller and Andrew Revkin in the New York Times, 16 December 2007, reported that at Bali 'China and other emerging powers did inch forward, agreeing for the first time to seek ways to make 'measurable, reportable and verifiable' emissions cuts.' That is consistent with how APEC individual action plans and collective action plans have evolved in APEC and is a long way from the rhetoric of many NGOs. vulnerability' - access to fossil fuels and renewable sources, options for sequestering emissions (including cessation of deforestation), and the potential size of employment and income shocks. Countries with high impact vulnerability and low source vulnerability should favour emission limits, and those with high source vulnerability and low impact vulnerability should resist any agreement. There is no clear pattern by level of development, and not much by region, although it is easy to see why Europe favours emission controls and why the US and Australia do not - dependence on coal is the most influential variable.

Much local reporting on Bali used a framework of 'most countries (including the EU and New Zealand)' against the US, which rather overlooks the importance of Asia. However, it was European observers, Gwyn Prins and Steve Rayner of the London School of Economics and Oxford, who observed bluntly that 'Kyoto was both a technical and a political failure' (Prins \& Rayner, 2007). Conventional economic analysis of cartels shows that Kyoto is inherently unstable. It is ironic that while original analysis is being done on how to manage the future of the WTO, an attempt is being made to build the UN Framework Convention on Climate Change into a copy of the existing WTO. An idealistic but forlorn yearning for solidarity is being given precedence over rational policy analysis.

The address at Bali of Lee Hsien Loong, prime minister of Singapore, was much more significant than recognised in New Zealand and by much of the international media. Lee called for an agreement that covers all developing and developed countries, acknowledges the importance of economic growth and respects the different situations of individual countries. He put a lot of emphasis on adaptation and technology development - and it is surely not difficult to predict that any international agreement will have to be some combination of American faith in technology and European insistence on emissions controls. Any agreement that covers all developing and developed countries will have to respect different circumstances in a manner which is much more subtle than the dichotomy of 'developed' and 'developing'.

The climate change debate needs some Asian pragmatism. There are uncertainties about the relationship between warming and carbon dioxide emissions, but policy should proceed on the basis 
that human activity is changing the atmosphere undesirably. There is justification for scepticism about 'tipping point' arguments which are used to generate a sense of urgency, but sober analysis may point to the desirability of early action. That is essentially an issue of cost-benefit analysis, in which the difficulties are only how to deal with very long-range but irreversible changes, difficulties which require new thought and are not helped by vehement assertion.

A major contribution to our policy debate is likely to come from across the Tasman. Professor Ross Garnaut is currently reviewing climate change policy for the new Australian government. He is a long-time student of Australia's relations with Asia, a former ambassador to China, and an academic and business economist who is endowed with deep participant and reflective knowledge of how APEC has developed. The review has its own website (www.garnautreview.gov.au), which already contains a good deal of material, including a paper by Garnaut which was discussed at PAFTAD (the Pacific Trade and Development Forum) in December. Like the analysis of Warwick McKibben, ${ }^{3}$ it identifies the need for various responses with co-ordination among them, rather than persisting with attempting to create a single cartel which is inherently unstable. ${ }^{4}$ More interestingly, the Garnaut paper advocates equal per capita emissions as the solution to how an international climate change agreement can eventually be constructed. It must be a long-term objective, since it is clearly not feasible to eliminate immediately or even quickly the very wide difference in energy usage between rich and poor countries, but it starts to define a path which accommodates economic growth and which deals with differences among nations while having consensus on an international effort. One of the primary conceptions of APEC was that it should reconcile Asian modes of agreement with American demands for reciprocity; the international trading system still requires knowledge and analysis that shows that reciprocity is not needed, and climate change is going to be another area of international negotiations where this issue will be

3 Conveniently summarised in his presentation to the PECC general meeting in Sydney in mid-2007 and available on www.anu.edu.au.

4 The McKibben analysis also deals with the hollow argument about trading system versus carbon tax. We need a trading system for the long term and taxes to give assurance about costs in the short term. The policy design issue is not to choose between them, but to build institutions and processes which ensure their compatibility over time. explored. Big powers are not going to give up reciprocity in a hurry, and the outlook is for a long period of continual discussion rather than completion of a single agreement. The School of Government should be preparing the analysts who will manage New Zealand's participation.

\section{Retirement income}

Climate change is not the only policy area where we need more attention to the international dimension, especially that of Asia. Our retirement income policy debate is not unnaturally much occupied with local questions. We will continue to explore the impact of tax incentives on aggregate savings (as distinct from the effectiveness of tax incentives in directing funds to favoured vehicles). We will also explore the consequences of demographic change, not in the popular terms of what can be afforded, but in recognising that conventional retirement 'ages' have been overtaken by changes in longevity (cf Retirement Commission, 2007).

However, we should expect the key issues to lie elsewhere, partly in domestic issues and partly in international ones. The common thread is diversity, and the School of Government and Institute of Policy Studies have made significant contributions to its elucidation (Boston, Callister \& Wolf, 2006; Boston \& Davey, 2006). Policy consideration of diversity is sometimes limited to ethnic and gender diversity, and even to the delivery of social services in ways that are congenial to distinctive ethnic and gender groups. Retirement income policy is affected more fundamentally by different values and preferences. Government policy was once widely thought of as aiming to relieve poverty among the aged. It is now most commonly thought of as ensuring that the aged have a standard of living commensurate with that of society as a whole. However, demographic trends are requiring that it be conceived as facilitating choices about the extent to which income earned during years of employment is deferred to support consumption in a lengthy period of activity, with lower income-earning capacity beyond a standard career followed by years among the older retired'. The government is more like a piggy bank than a welfare agency (Barr, 2001). Individual experiences will vary, especially through differential health status, the extent to which lifetime careers provide opportunities for post-retirement income-earning, and different preferences about enjoying income as it is earned or 
preparing for delayed gratification. ${ }^{5}$ Policy will have to cope with diversity. The thought, which is valued by many, that we should aim for equality among the retired will be in conflict with recognition of diversity. That is the most important domestic influence on retirement income policy for which we should be preparing our graduates.

Some of the international elements are obvious. Migration can affect the speed of the most significant underlying demographic change, although its influence is small relative to fertility trends. Migration will greatly affect where and how individuals build up entitlements to post-employment income. As we move from migration being mostly a permanent move from one country to another, to periodic relocation in the course of employment, and to building families across international borders, retirement income policy will have to adapt. Some international elements are even less obvious. The retirement incomes of the future depend above all on the productivity of the future economy funds build up entitlements to share in what is produced in the future rather than create stores of future income. The effective future productivity can be enhanced by investing in countries with younger populations (and so a higher ratio of producers to total population). Our long-held convention of fostering investment which generates current domestic employment will become increasingly in conflict with retirement income policy. Furthermore, we will have a direct interest in productivity trends elsewhere. It is not fanciful to contemplate that the most important decisions for the future of our retirement income policy may be those of the Chinese government about how China participates in international capital markets.

\section{Education policy}

Education policy has engaged the attention of several in the school. I have been concerned with some responses to the travails of NCEA and the Scholarship exam, while others, especially Jonathan Boston, have looked at issues such as the Performance-Based Research Fund. But as with retirement income policy, we should try to look beyond such issues, important though they are, and isolate what is the underlying trend which will generate future emerging issues.

5 Preferences will themselves be influenced by social, ethnic and other groupings; they are not entirely autonomous.
In my view, this remains acceptance that 'lifetime education for all' is an enduring response to the way that modern societies, economies and political systems require greater cognitive abilities in the population as a whole than used to be the case, so that an appropriate education system now has to be built on recognition of achievement and not on sorting out an elite to benefit from further education. There is a large degree of agreement in principle to this conclusion, but it often dissipates when it comes into tension with conventional and familiar processes within teaching institutions. The School of Government has not been entirely free from nostalgia for the days when 'standards' were adequately monitored by the performance of top-performing students, and sufficiently protected by imposing demanding failure rates. Other parts of the university, and some other parts of the education sector, are much further behind required attitudinal changes.

Even the School of Government is inclined to retreat too readily towards thinking of itself as a provider of knowledge rather than a provider of opportunities for students to develop knowledge.

The next step is to dump our most natural and mistaken metaphor - education as the filling of empty minds - and recognize that we learn by extrapolating, testing, modifying and recombining mental models of the world.

(Saleton, 2007)

The relevant 'mental models' are not only those we inherit from the European tradition, or which originate in the contemporary academic world led from the United States in which we most frequently participate. We want to be equipped to engage with Asian thinking too. In education policy, the most obvious manifestation of this is the significance of realising that the eighteenth-century Enlightenment was not a universal experience, and that relative valuations of freedom and order can vary. More prosaically, we can learn from Asian experience about the optimal balance between encouraging teacher initiative and using centralised lesson-preparation and directed delivery through specialised teachers. In the wider policy fields discussed above, we should ensure that our education programmes equip graduates to understand the different implications of Chinese ideas of 'harmony', whether between economies or between governments and citizens. This should be the objective of Asia literacy, and it is a long way from encouraging the teaching of Asian 
languages for utilitarian purposes like trade promotion, although learning Asian languages can be a suitable vehicle for the understanding which we seek.

\section{Conclusion}

I have structured this discussion around issues which have been among my chief interests in the last five years. Because I have been in a good position to watch the work of colleagues, I could easily use other examples, notably relations between New Zealand and the Pacific, the growth of e-Government, and trends in public management. The common thread is the role of academic ideas in making connections between what may be left separate, in recognising the challenge of new initiatives to deeply-held inherited ideas, and in showing the implications of what looks attractive until it is really understood.

What the School of Government has learned in its first five years - perhaps not entirely, but to a large extent is that we are not the fount of knowledge, but we can provide opportunities for public servants to come together with academics, share their experiences and learn together, creating, disseminating and maintaining knowledge. We thus promote the strategic developments which public servants will have to manage in the future.

\section{References}

Barr, N. (2001) The Welfare State as Piggy Pank: information, risk, uncertainty, and the role of the state, Oxford \& New York: Oxford University Press

Boston, J., P. Callister \& A. Wolf (2006) The Policy Implications of Diversity, Wellington: Institute of Policy Studies

Boston, J. \& J. Davey (eds) (2006) Implications of Population Ageing: opportunities and risks, Wellington: Institute of Policy Studies

Buys, P., U. Deichman, C. Meisner, Thao Ton Thal \& D. Wheeler (2007) Country Stakes in Climate Change Negotiations: two dimensions of vulnerability, World Bank policy research paper 4300, August

Desker, B. (2007) 'ASEAN: act on climate change', RSIS Commentaries 109/2007

Hawke, G. (forthcoming) 'Reflections on the partnership between the School of Government and the state services: where to from here?, Public Sector
MFAT (2007), Our Future with Asia, Wellington: Ministry of Foreign Affairs and Trade

Prins, G. \& S. Rayner (2007), Wall Street Journal,10 December, p.19

Retirement Commission (2007) 2007 Review of Retirement Income Policy, December, www.retirement. org.nz/2007_review.html

Saleton, W. (2007), review of S. Pinker, The Stuff of Thought: language as a window into human nature, in New York Review of Books, 22 September

Gary Hawke recently retired as

Professor of Economic History and head of the School of Government at Victoria University of Wellington. He was made a CNZM in the 2008 New Year's Honours for his services to education and economics. 